\title{
Gerenciamento de riscos na cadeia de suprimentos: auditoria em fornecedores
}

Eventos de riscos na cadeia de suprimentos são inerentes dentro de indústrias e organizações, podendo influenciar diretamente na competitividade e lucratividade. Para tanto, é fundamental um método de gerenciamento de risco na cadeia de suprimentos. Esse estudo visou identificar a auditoria em fornecedores como um possível método para o gerenciamento de riscos na cadeia de suprimentos. Realizou-se uma revisão da literatura para identificar e definir os temas abordados, e como pesquisa foi avaliado uma empresa multinacional no segmento de peças automotivas. Para a metodologia, aplicou-se entrevistas aos setores da organização para analisar a perspectiva dos funcionários em relação aos riscos dos fornecedores e do método de auditoria aplicado. Na etapa posterior foi coletado documentos de relatórios de auditorias e feito uma análise detalhada. Foi possível identificar que existe uma correlação da norma ISO 31000 (2015) "Gestão de riscos Princípios e diretrizes" e o método de auditoria, assim como também foi comprovado que o método de auditoria conduz para a melhoria de desempenho do fornecedor.

Palavras-chave: Gerenciamento de Risco; Gerenciamento de Risco na Cadeia de Suprimentos; ISO 31000 (2009); Auditoria.

\section{Supply chain risk management: supplier audit}

Risk events in the supply chain are inherent within industries and organizations, and can directly influence competitiveness and profitability. To this end, a method of supply chain risk management is fundamental. This study aimed to identify supplier auditing as a possible method for the management of risks in the supply chain. A review of the literature was carried out to identify and define the topics covered, and as a research, a multinational company in the segment of automotive parts was evaluated. For the methodology, interviews were conducted with the organization's departments to analyze the employee's perspective on supplier's risks and the applied audit method. In the later stage, audit reports were collected and a detailed analysis was done. It was possible to identify that there is a correlation between ISO 31000 (2015) "Risk management - Principles and guidelines" and the audit method, as well as proven that the audit method leads to a better supplier performance.

Keywords: Risk Management; Supply Chain Risk Management; SCRM; ISO 31000 (2009); Audit.

\section{Topic: Teoria Geral da Administração}

Reviewed anonymously in the process of blind peer.

Tommy Figueiredo Brasil

Universidade Federal Fluminense, Brasil

http://lattes.cnpq.br/3551727883252462

tommybrasil@hotmail.com

\section{Ualison Rébula de Oliveira}

Universidade Estadual Paulista Júlio de Mesquita Filho, Brasil

http://lattes.cnpq.br/6460931837390456

ualison.oliveira@gmail.com
Received: 04/01/2017

Approved: 05/03/2017
Referencing this:

BRASIL, T. F.; OLIVEIRA, U. R.. Gerenciamento de riscos na cadeia de suprimentos: auditoria em fornecedores. Revista Brasileira de Administração Científica, v.8, n.1, p.19-31, 2017. DOI: http://doi.org/10.6008/SPC2179-684X.2017.001.0002

DOI: 10.6008/SPC2179-684X.2017.001.0002 


\section{INTRODUÇÃO}

Com o avanço tecnológico e as transformações do cenário industrial do século 21 , cria-se um aumento na complexidade das organizações assim como na interação entre as mesmas. Em conjunto a esta evolução, surgem riscos que antes não eram tão importantes, ou em alguns casos até ignorados. Segundo Tang et al. (2011), gerenciar os riscos relacionados à cadeia de suprimentos são fundamentais para a sobrevivência de qualquer organização.

Considera-se que, nos últimos anos, tem-se dado cada vez mais importância e foco à cadeia de suprimentos. Este possui a responsabilidade por abastecer o meio produtivo, fornecendo o input de insumos ao processo. "Uma organização e seus fornecedores são interdependentes e uma relação mutuamente proveitosa aumenta, para ambos, a habilidade de agregar valores" (ABNT, 2005). Segundo Purdy (2010), a qualidade e confiabilidade da matéria prima são primordiais para garantir o fluxo contínuo dentro da organização. As falhas que ocorrem no abastecimento, sejam falhas devido a não qualidade ou o não cumprimento do prazo de entrega, se derivam em maior parte como falhas que ocorrem dentro do processo do fornecedor.

Para Giunipero et al. (2004), o prejuízo financeiro gerado por essas falhas são de grande impacto, gerando risco sobre a lucratividade e competividade das organizações, podendo em muitos casos afetar diretamente a sobrevivência da mesma. Tang define o supply chain risk management (SCRM) como o gerenciamento dos riscos na cadeia de suprimentos por meio da coordenação e colaboração entre os fornecedores, de modo a assegurar a rentabilidade e continuidade do abastecimento. A configuração da cadeia de suprimento e a capacidade de coordenação entre o fornecedor e o cliente é uma das maiores influencias no gerenciamento de risco (HOLLSTEIN et al., 2013).

Para Christopher et al. (2004), a vulnerabilidade nas cadeias de suprimento e as perturbações geradas no relacionamento entre o cliente e fornecedor aumentaram consideravelmente. Muitas empresas têm experimentado mudanças em seus modelos de negócios, por exemplo, a adoção de práticas 'lean', assim como a terceirização de atividades importantes. Para a Associação Brasileira de Normas Técnicas, a melhoria contínua é um requisito obrigatório para as organizações e tem como conceito a eliminação de desperdícios e atividades de valor não agregado, favorecendo na redução de custo dos processos industriais. Ao contrário da melhoria contínua, muitas empresas executam ações de redução sobre atividades de valor agregado, afetando diretamente a qualidade percebida pelo cliente.

Segundo Fabiani et al. (2015), a redução no quadro de funcionários é um exemplo de ação que pode ser inadequada para garantir o requisito do cliente final. Em virtude da facilidade em serem colocadas em prática versus o benefício direto sobre o impacto financeiro na empresa, ações inconsequentes muitas vezes são tomadas. Em decorrência de ações semelhantes a essa é possível observar a fragilidade que é gerada no processo do fornecedor, afetando diretamente a cadeia de suprimento do cliente.

Christopher et al. (2004) argumenta que a confiança na cadeia de suprimento aumentará em proporção à qualidade das informações. Deve haver uma estratégia destinada a mitigar os riscos da cadeia 
de suprimentos por meio do aumento na visibilidade da organização fornecedora. Para Christopher et al. (2004), a falta de visibilidade gera consequências indesejadas para diversas áreas da empresa. No quadro 1 é possível identificar as áreas da empresa e os respectivos resultados devido à falta de confiabilidade.

Quadro 1: Consequências da falta de confiabilidade.

\begin{tabular}{|l|l|}
\hline Áreas da Empresa & Resultado da Falta de confiabilidade: \\
\hline Vendas & Ordem de compra excessiva para garantir estoque "buffer" para atendimento ao cliente final. \\
\hline Atendimento ao Cliente & $\begin{array}{l}\text { Impossibilidade em fornecer informações precisas sobre disponibilidade } \\
\text { Pode ter a necessidade de solicitar estoque "buffer" para atender cliente. }\end{array}$ \\
\hline Operações & $\begin{array}{l}\text { Criação de estoque excessivo ou necessidade de ter excesso de capacidade para compensar a falta de confiança de } \\
\text { outras áreas }\end{array}$ \\
\hline $\begin{array}{l}\text { Marketing } \\
\text { Prima }\end{array}$ & $\begin{array}{l}\text { Atrasos no lançamento de novos produtos, devido à incerteza do abastecimento. } \\
\text { Liquidações ou grandes descontos devido ao excesso de estoque no final do ciclo de vida do produto. }\end{array}$ \\
\hline
\end{tabular}

Fonte: Christopher et al. (2004).

Atualmente os mercados estão se tornando cada vez mais globais, ao passo que as necessidades dos clientes estão ficando cada vez mais sofisticadas e em rápida mudança. O conhecimento dos clientes a respeito dos produtos e das organizações que fabricam os mesmos são fundamentais para o Supply Chain Management (SCM) (NATOUR et al., 2011).

Para Platts et al. (1990), um dos meios para levantamento de informações é utilizando a técnica de 'auditorias'. Por meio da execução de auditorias, muitas empresas obtiveram informações importantes que permitiram formular estratégias das organizações, mitigando riscos e aumentando o desempenho de manufatura (ROBSON et al., 2007). Com este estudo pretende-se responder as seguintes perguntas: A auditoria em fornecedores seguem os passos de gerenciamento de risco abordados na ISO 31000 (2009)?; Foi comprovado eficácia das auditorias para o desempenho dos fornecedores?; e É possível utilizar auditoria como meio de SCRM?.

Neste estudo utilizou-se de uma análise documental em uma empresa do segmento automobilístico, sendo esta também um fornecedor para diversas montadoras de veículos. A empresa é de grande porte, multinacional de origem Italiana. Para o estudo, questionamentos foram feitos e também houve o levantamento de dados com os funcionários dos setores de qualidade, logística, compras e manufatura. A presente pesquisa tem como principal objetivo a proposição de um modelo conceitual de auditoria para gerenciamento de riscos na cadeia de suprimento.

\section{REVISÃO TEÓRICA}

\section{Risk Management (RM)}

A norma ISO 31000 (2009) publicada pela Organização Internacional de Normalização sobre o título 'Gestão de riscos - Princípios e diretrizes' define risco como o efeito da incerteza nos objetivos, sendo o gerenciamento de riscos as atividades coordenadas para dirigir e controlar uma organização no que se refere a estes efeitos. O gerenciamento de risco é um processo realizado por meio de aplicação de procedimentos e métodos com o objetivo de mitigar a probabilidade das falhas ocorrerem e consequentemente reduzir os riscos associados a ela. 
Segundo Tang et al. (2011), devido à globalização e aumento na competitividade das organizações, há uma demanda crescente do tema gestão de riscos. De acordo com Hollstein et al. (2013), riscos na cadeia de suprimento diferem daqueles riscos internos dentro da organização. As diferenças surgem na intensidade da cooperação entre as empresas, criando dependências recíprocas. Quanto maior a dependência e interligação das empresas, maior o risco associado.

A norma ISO 9001, em sua última revisão incorporou como requisito mandatório a necessidade de estabelecer uma abordagem sistemática ao risco. Ao adotar uma abordagem baseada no risco, uma organização torna-se proativa ao invés de puramente reativa, prevenindo ou reduzindo os efeitos indesejados e promovendo a melhoria contínua.

Para Purdy (2010), cada organização precisa criar ou revisar seu sistema de gestão de riscos para adequar seus processos, estrutura, perfil de risco, e políticas. Organizações grandes e complexas podem requerer uma hierarquia de planos de gestão de risco, mas deve sempre haver um plano global para a organização que descreve as estratégias amplas para serem seguidas. Embora todas as organizações gerenciem os riscos em algum grau, a norma ISO 31000 estabelece um número de princípios que precisam ser atendidos para tornar a gestão de riscos eficaz.

Esta norma recomenda que as organizações desenvolvam, implementem e melhorem continuamente uma estrutura, cuja finalidade é integrar o processo para gerenciar riscos na governança, estratégia e planejamento, gestão, processos de reportar dados e resultados, políticas, valores e cultura em toda a organização. A ISO 31000 (2009) padroniza o gerenciamento de risco em sete passos conforme ilustra a figura 1.

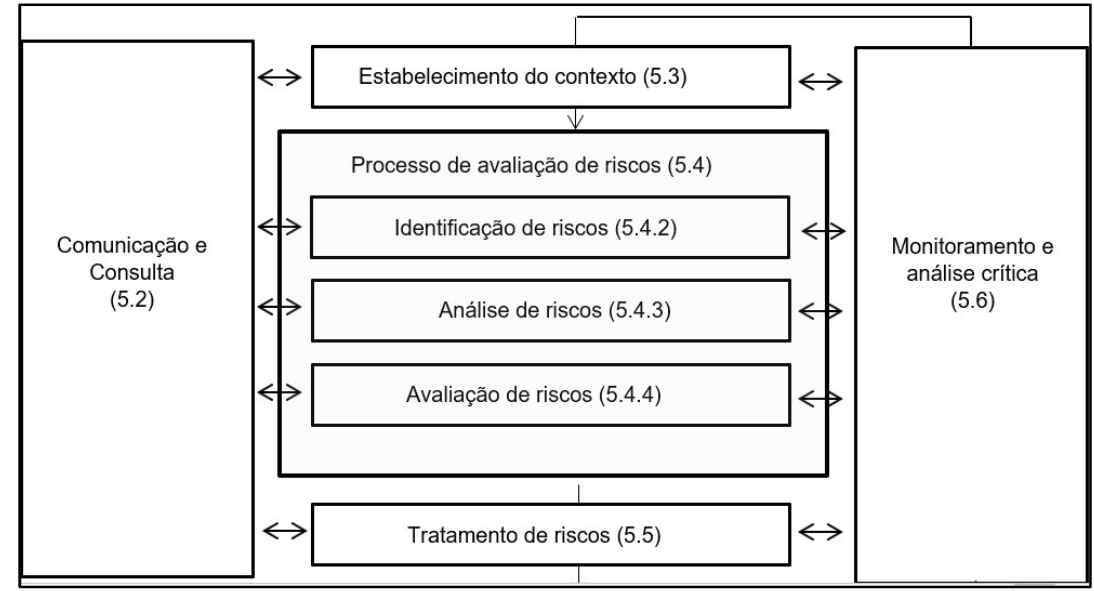

Figura 1: Processo de Gestão de Risco. Fonte: ABNT (2009).

Conforme a ABNT (2009), a padronização das etapas de gerenciamento de risco definem comunicação e consulta: se trata do planejamento da comunicação entre as partes interessadas no gerenciamento de risco, principalmente na identificação da percepção dos acionistas. Neste primeiro passo o ponto de vista das diferentes partes podem ter um impacto significativo sobre as decisões tomadas; estabelecimento do contexto: define os parâmetros internos e externos a serem levados em consideração 
ao gerenciar os riscos. Nesta etapa convém que seja estabelecida a estratégia e objetivo das atividades da organização, assim como os recursos requeridos.

Por conseguinte, identificação dos riscos: fornece o entendimento da fonte dos riscos junto a sua causa, efeito e área afetada. A finalidade é gerar uma lista com itens que podem afetar a realização de um determinado objetivo. Cada organização deve adotar o método ou procedimento mais adequado à própria realidade para identificação destes riscos; análise de Riscos: envolve o entendimento e compreensão dos riscos envolvidos para ter um melhor entendimento e definição da estratégia para lidar com os mesmos. A análise do risco envolve o conhecimento sobre a probabilidade deste em ocorrer; avaliação de Riscos: define a prioridade dos riscos para a implementação do tratamento. Envolve tomada de decisão sobre o nível do risco e prioridade de atenção por meio da aplicação do critério desenvolvido na ocasião em que o contexto foi estabelecido.

Subsequentemente, tratamento de riscos: são as ações aplicadas sobre o risco detectado. Compreende a avaliação e seleção das potenciais ações, levando em consideração a análise de custos e benefícios; monitoramento e análise crítica: checagem ou vigilância sobre os riscos. O monitoramento e a análise crítica preveem a tomada de ação no momento em que surgirem novos riscos que mudem os riscos existentes, como produto de mudança nos objetivos organizacionais ou nos ambientes interno e externo (PURDY, 2010).

\section{Supply Chain Management (SCM)}

Segundo Ram et al. (1995), o gerenciamento da cadeia de suprimentos (SCM) tem por objetivo desenvolver funções de compra de materiais, transformar matérias-primas em produtos acabados e semiacabados, e distribuir estes produtos aos consumidores. Para Ahmed et al. (2002), a cadeia de suprimento consiste em todas as etapas envolvidas, direta ou indiretamente, no cumprimento de um pedido do cliente. A cadeia de suprimento não só inclui o fabricante e fornecedores, mas também transportadores, armazéns, lojas, e os próprios clientes.

O SCM encara a cadeia de suprimentos e as organizações como uma entidade única e traz uma abordagem de sistemas para entender e gerenciar as diferentes atividades necessárias para coordenar o fluxo de produtos e serviço, com o intuito final de servir o cliente (BANDALY et al., 2013). Para Ballou (2006), o termo SCM é relativamente novo, porém o conceito se estende por mais de 40 anos. Na figura 2 é possível observar a evolução do que atualmente é denominado de gestão da cadeia de suprimentos desde o ano de 1960. Uma cadeia de suprimentos é definida como uma equipe de 3 ou mais entidades (organizações ou indivíduos) diretamente envolvidas num fluxo upstream e downstream de bens, serviços e informações para atender ao consumidor (MENTZER et al., 2001). Na figura 3 identifica-se o fluxo do SCM. 


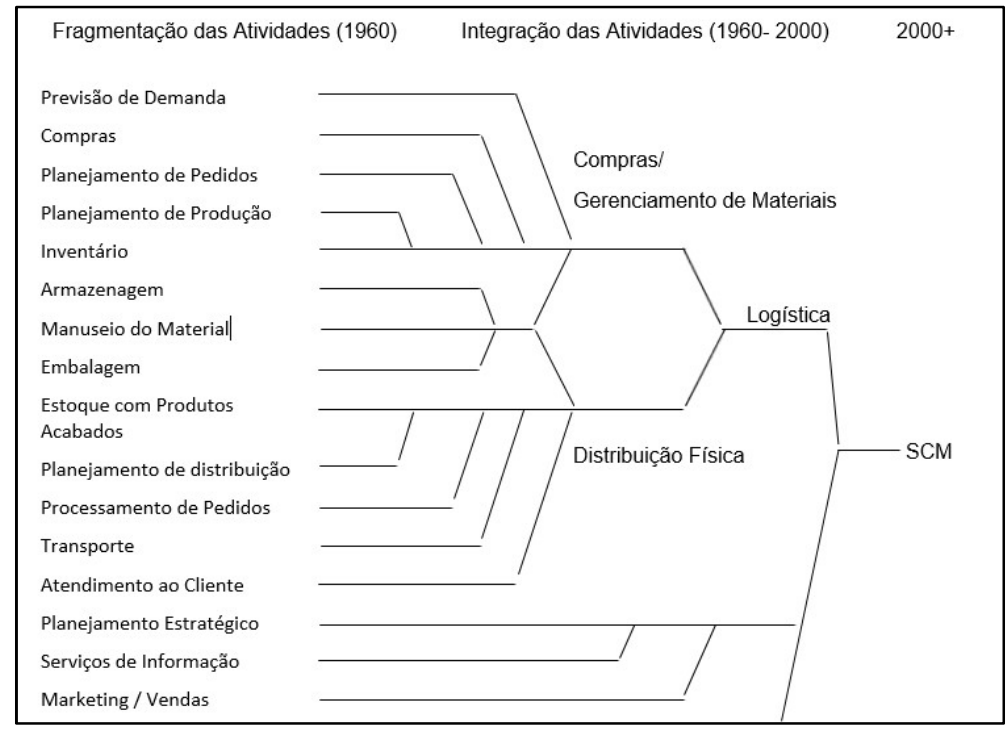

Figura 2: Evolução do SCM. Fonte: Ballou (2006).

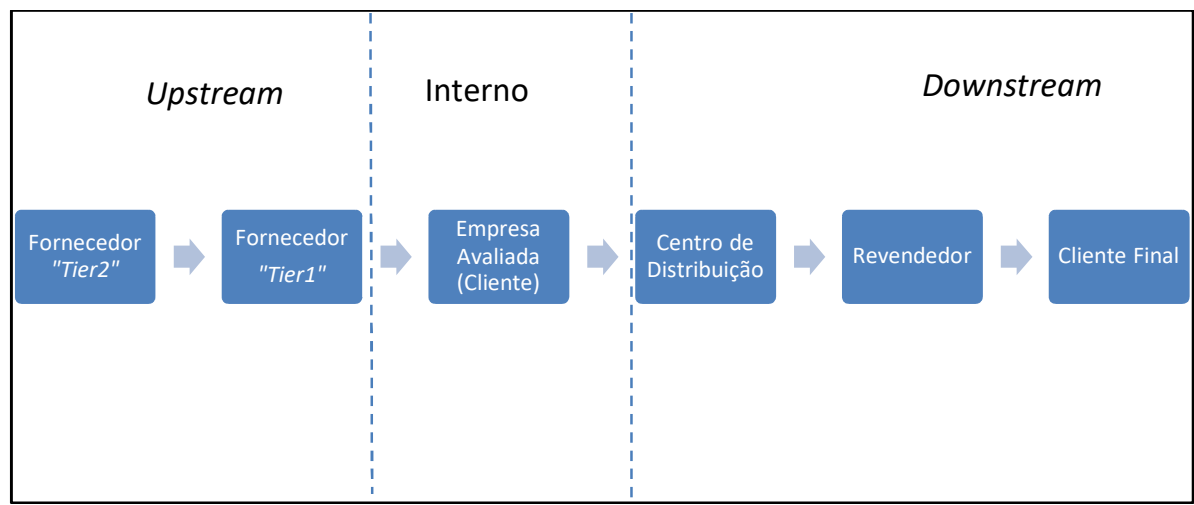

Figura 3: Fluxo do SCM.

A produção no nível operacional é associado a gestão de produção, no entanto, certas características do processo são projetadas para integrar o gerenciamento de operações internas com atividades na cadeia de suprimentos (CROXTON et al., 2001). Existe uma necessidade para as empresas gerirem não só a si mesmas, mas também suas relações com seus fornecedores (LAMBERT et al., 2001). Valor e satisfação do cliente são reconhecidos como fatores necessários para alcançar vantagem competitiva e lucratividade para as empresas individuais, bem como para a cadeia de suprimentos como um todo (MENTZER et al., 2001).

\section{Supply Chain Risk Management - SCRM}

O gerenciamento de riscos está se tornando uma das principais preocupações das organizações, sendo necessário para a sobrevivência no ambiente de negócios competitivo. Assim, o gerenciamento de riscos da cadeia de suprimento (SCRM) surgiu como uma extensão natural da gestão da cadeia de suprimento com o objetivo principal de identificar as fontes potenciais de riscos e sugerir medidas adequadas para mitigálas (SINGHAL et al., 2011). A figura 4 mostra a interseção do conceito de SCRM com a sobreposição dos conceitos de Risk Management (RM) e Supply Chain Management (SCM). 


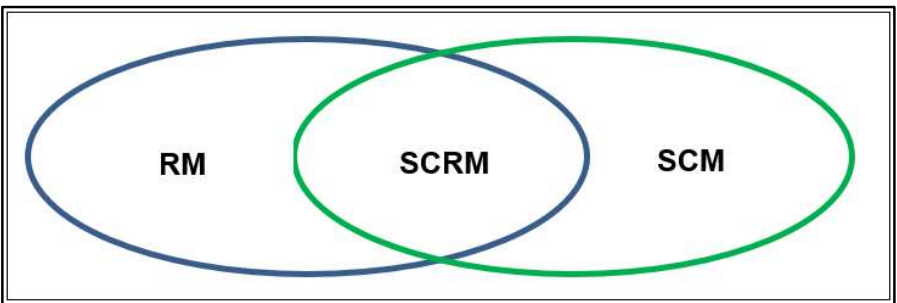

Figura 4: Evolução do SCRM. Fonte: Blos et al. (2009)

Segundo Hollstein et al. (2013), o SCRM está ganhando cada vez mais importância. O SCRM tem como objetivo mitigar os riscos que afetam a cadeia de suprimento, reduzindo, anulando ou eliminando a probabilidade dos riscos e a magnitude do impacto na rede de suprimentos. Segundo Hollstein et al. (2013), o SCRM está ganhando cada vez mais importância. Seu caráter interdisciplinar é marcado por tensões e interdependências entre fatores quantitativos e qualitativos.

\section{Auditorias}

A norma da ABNT ISO 19011 é a principal norma que fornece diretrizes para a realização de auditorias conduzidas por clientes em seus fornecedores. A norma define auditoria como sendo um método eficaz e confiável em apoio às políticas de gestão e controles, fornecendo informações sobre as quais uma organização pode agir para melhorar seu desempenho. Para Attie (1998), a auditoria é uma abordagem baseada em evidencias e de forma amostral, uma vez que uma auditoria é realizada durante um período de tempo finito e com recursos limitados. A mesma deve ser conduzida por um auditor competente e com interesses independentes da área ou organização sendo avaliada. Segundo Attie (1998),

$O$ auditor deve ser absolutamente independente e imparcial na interpretação de tudo que Ihe for apresentado, atestando a cada dado um pronunciamento conclusivo. A independência necessita orientar o trabalho do auditor no sentido da verdade, evitando interesses, conflitos, vantagens, sendo factual em suas afirmações. Seu trabalho precisa ser encaminhado com observância às normas de auditoria e aos padrões e técnicas aplicadas ao exercício de sua função, valendo-se, se for o caso, de opiniões de outras profissões técnicas quando o momento assim o exigir.

Convém que uma organização que necessita realizar auditorias estabeleça um programa de auditoria. Segundo a ABNT (2015), um programa de auditoria deve ser planejado, levando em consideração a situação e a importância dos processos e áreas a serem auditadas, bem como os resultados de auditorias anteriores. A implementação do programa de auditoria deve ser monitorada e medida para assegurar que seus objetivos sejam alcançados. A figura 5 ilustra o fluxo do processo para a gestão de um programa de auditoria.

Segundo a ISO 19011 (2012), auditoria é um processo sistemático, documentado e independente para obter evidências e avalia-las, objetivamente, para determinar a extensão na qual os critérios são atendidos. Segundo Attie (1998), para auditar determinado processo e garantir o cumprimento de elementos pré-estabelecidos, deve-se utilizar grades de auditorias (checklists). Após a definição do programa de auditoria, segue-se para o passo de execução da avaliação. O fluxograma da Figura 6 fornece uma visão geral das atividades típicas de auditoria. Kleindorfer et al. (2005) argumenta que a prevenção do risco é menos 
custoso do que a tratativa do mesmo, ou seja, aplicar corretamente uma auditoria para detectar os potenciais riscos é melhor do que atuar sobre os efeitos negativos após materialização do efeito do risco.

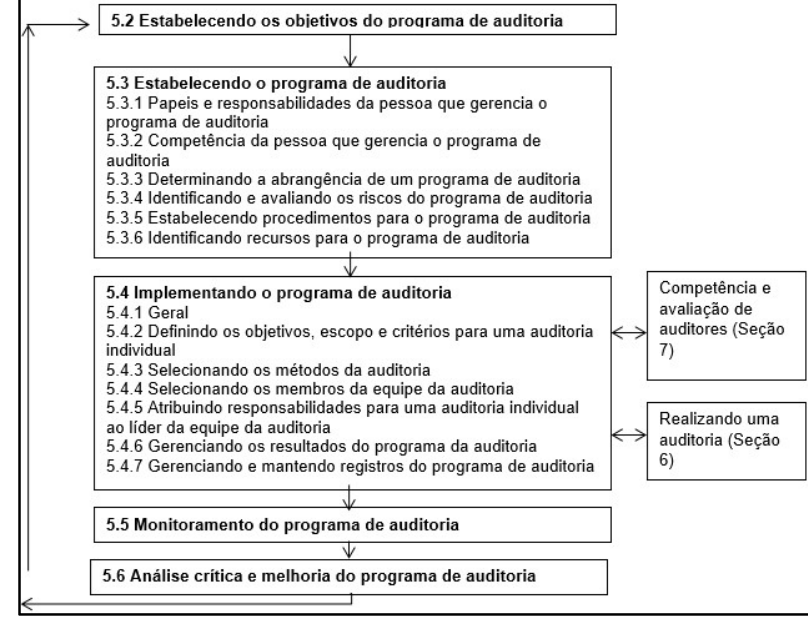

Figura 5: Etapas de uma auditoria. Fonte: ISO 19011 (2012).

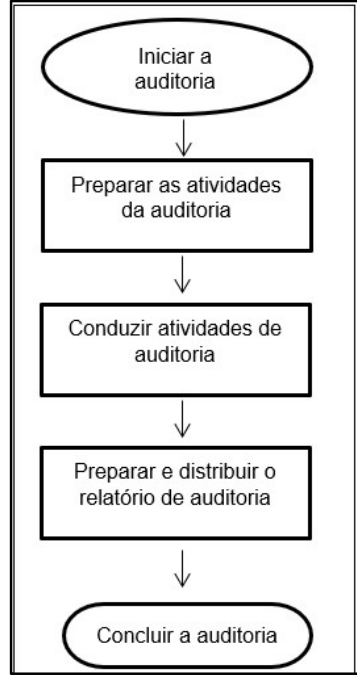

Figura 6: Fluxo de execução da auditoria.

\section{METODOLOGIA}

É de extrema importância a aplicação de um método para mitigar o efeito dos riscos associados ao fornecedor na cadeia de suprimento. A capacidade de identificação dos riscos requer o conhecimento da empresa sobre os componentes mais críticos no que diz respeito ao seu processo produtivo e fornecedores, a fim de concentrar esforços nas áreas mais vulneráveis de cada operação (KLEINDORFER et al., 2005). Nesta pesquisa propõe-se a adoção da técnica de auditoria de processo como meio para gerenciamento de riscos na cadeia de suprimento. Para fundamentar a proposta, foi realizada uma análise documental sobre os relatórios de auditorias de processo em fornecedores da empresa durante o ano de 2015.

Utilizou-se de uma abordagem de 4 passos para execução da pesquisa: entrevista aos setores de qualidade, logística, compras e manufatura; levantamento dos relatórios de auditorias; análise dos relatórios; e correlação dos relatórios de auditoria com o posterior desempenho do fornecedor. Por meio do primeiro passo foi possível levantar informações importantes que direcionasse o restante da pesquisa, pois utilizouse da percepção dos funcionários que estão presentes no cotidiano da empresa. O levantamento dos relatórios de auditorias foi um processo necessário para obter evidências documentadas do desempenho dos fornecedores. Para esta etapa foi consultado o setor de qualidade da empresa, responsável pelo planejamento e execução de auditorias em fornecedores.

O terceiro passo consistiu em uma análise detalhada dos relatórios, para que então pudesse haver um melhor entendimento de como estas auditorias são executadas e quais são as atividades ligadas às etapas do SCRM. Com a análise do relatório, pretende-se mapear em cada fornecedor o desempenho do mesmo. As auditorias foram executadas pela empresa em seus fornecedores sempre quando havia algum risco apresentado. Seja este risco um risco na quebra da qualidade do produto ou eventual distúrbio no prazo de entrega. 
Os relatórios de auditoria dos fornecedores possuem informações sobre o índice de qualidade do mesmo (IQF), que é um índice baseado em uma equação que leva em consideração 'prazo de entrega' e 'qualidade do produto entregue'. Para tanto, correlacionou-se os resultados das auditorias executadas em 2015 com o desempenho do fornecedor no primeiro semestre de 2016, permitindo desta forma analisar o êxito destas auditorias.

\section{RESULTADOS E DISCUSSÃO}

Ao entrevistar o setor de manufatura da empresa, foi evidenciado o impacto que os fornecedores trazem para o processo interno da organização. A supervisão da produção informou que quando há um problema de qualidade no produto relacionado ao fornecedor, muitas vezes gera-se parada de linha. A parada de linha afeta diretamente os objetivos de desempenho da manufatura, portanto é de interesse comum da organização em mitigar as falhas geradas pelos fornecedores.

O departamento de logística informou que não são somente os problemas de qualidade no produto, mas também constantemente ocorrem atrasos ou até a falta de entrega. Foi informado pela gestão do setor que somente no ano de 2015 houve 3 paradas de linha no cliente final devido à falta de abastecimento de peças. Em todos os casos no qual determinado problemas são de origem do fornecedor, o departamento de qualidade é comunicado para imediata tratativa junto ao mesmo.

O departamento de qualidade é responsável pela aplicação de métodos de análise e solução de problemas, assim como execução de auditorias internas e em fornecedores. Ao questionar a gestão da área sobre a evolução dos fornecedores, foi informado que desde o momento em que compras incluiu o critério de auditoria para validação de um novo fornecedor, aumentou-se consideravelmente a qualidade dos mesmos.

Desde o ano de 2012 a empresa implementou em procedimentos internos um fluxo de validação de fornecedores, definindo que os mesmos devem possuir não somente requisitos como a certificação ISO 9001, mas também a aprovação de um auditor qualificado. Observou-se também que o ano com mais recursos destinados à auditoria foi o ano de 2015. A partir desta informação, concentrou-se a pesquisa coletando e avaliando os relatórios de auditorias produzidos neste intervalo.

No ano de 2015 foram executadas pela empresa avaliada um total de 21 auditorias, sendo que, houve alguns casos onde um mesmo fornecedor recebeu mais de uma auditoria. Ao todo, são 15 fornecedores avaliados. Estas auditorias foram todas realizadas em fornecedores de primeiro nível, ou seja, aqueles que fornecem direto à empresa avaliada. Estes fornecedores se enquadram dentro das categorias: fornecedores de chapa de aço; fornecedores de componentes estampados; fornecedores de porcas e parafusos; fornecedores de lubrificantes; e. fornecedores de embalagem. O gráfico 1 demonstra a quantificação dos fornecedores por categoria. 


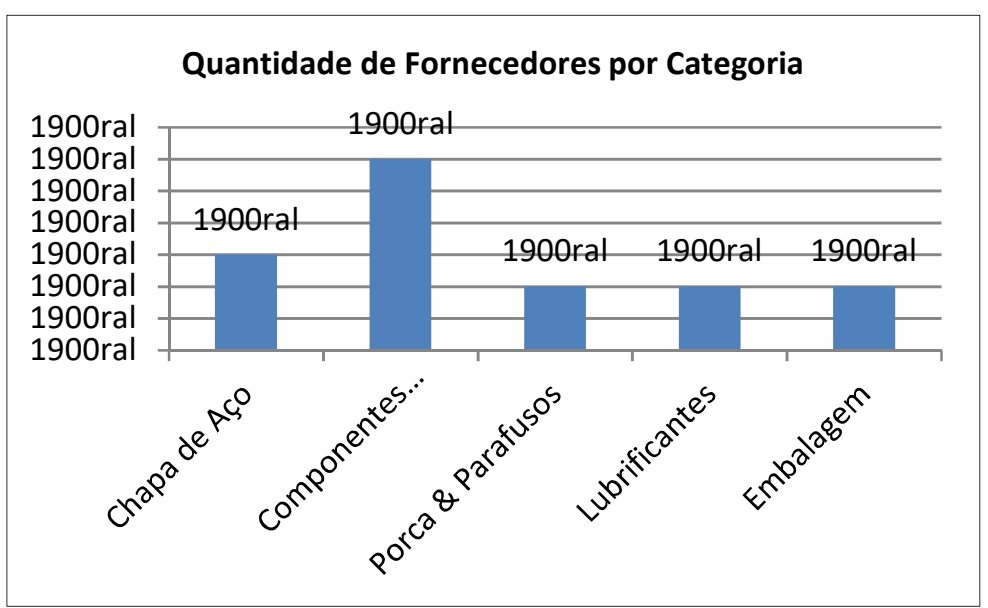

Gráfico 1: Fornecedores por categoria.

Na terceira etapa, houve uma análise detalhada sobre os relatórios. No relatório de cada auditoria está mencionado a nota de índice de qualidade fornecedor (IQF) do mês corrente da auditoria. Esta nota varia em uma escala de 0 a 100, sendo que quanto maior a pontuação melhor é o resultado do fornecedor. Identificou-se que grande parte das auditorias foram realizadas em fornecedores com nota abaixo de 70 pontos, pois a empresa adotava como regra que sempre quando um fornecedor permanecesse 3 meses seguidos abaixo de 70 pontos, o mesmo deveria ser auditado. Em alguns casos o fornecedor foi auditado para cumprimento da programação anual de auditoria, uma agenda estabelecida no início de cada ano. A nota do relatório de auditoria colabora para acompanhar a posterior evolução deste fornecedor, demonstrando o potencial êxito da auditoria. No gráfico 2, pode-se identificar a pontuação dos 15 fornecedores no momento da auditoria.

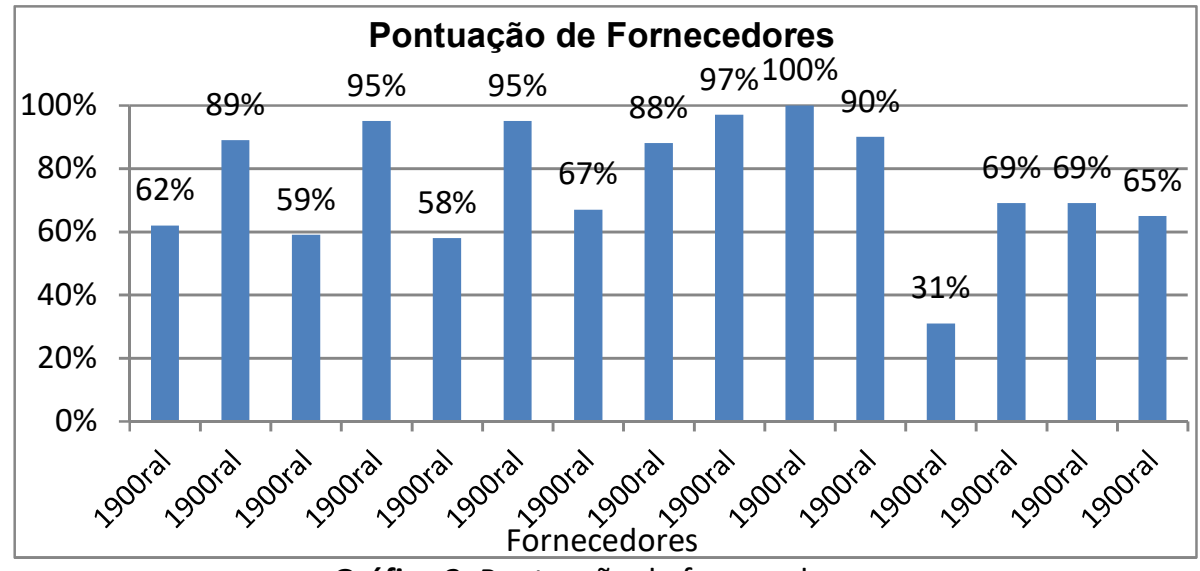

Gráfico 2: Pontuação de fornecedores.

As auditorias são realizadas na planta produtiva do fornecedor e possuem duração de 2 dias. Um auditor qualificado se desloca até o local de auditoria e executa a mesma por meio de um checklist de auditoria. Este checklist é uma grade específica da empresa, sendo que cada cliente pode elaborar de acordo com sua necessidade. A grade de auditoria garante que todos os processos da organização são avaliados, desde a parte produtiva (recebimento até a expedição final do produto) quanto as partes administrativas (vendas, engenharia, compras, recursos humanos). 
O objetivo de usar a grade de auditoria é garantir que todos os requisitos pré-estabelecidos são cumpridos e que não há potenciais riscos de afetação na qualidade e entrega ao cliente. O uso de uma determinada grade também elimina a possível subjetividade do auditor, garantindo que todos os fornecedores são avaliados em um mesmo critério.

Foi evidenciado que os itens verificados na grade de auditoria são todos os itens que podem gerar um efeito de um determinado risco ao cliente, tendo como os itens de maior importância: desenvolvimento do projeto: garante que a engenharia do processo foi desenvolvida de forma correta, cumprindo todos os requisitos pré-estabelecidos pelo cliente; aquisições: verifica para que tenha um método de garantir a qualidade da matéria prima adquirida.

A documentação dos fornecedores de segundo nível são avaliadas: embalagem e Identificação: a forma como o fornecedor acondiciona seus produtos, evitando qualquer desvio sobre a integridade do mesmo. A identificação também é avaliada, uma vez que uma identificação errada pode gerar um produto não conforme em processos posteriores; documentação de Processo: verifica se todos as instruções e procedimentos de trabalho estão corretos, minimizando os riscos para que se tenha uma falha operacional em função das informações disponíveis ao operador; treinamento: a forma na qual os funcionários foram treinados, assim como o conhecimento e qualificação.

Os relatórios avaliados foram elaborados após a execução da auditoria e identificação das não conformidades. Estes itens apontados como requisitos que não estão sendo cumpridos são listados em um plano de ação, onde para cada item existe um responsável e prazo para adequação. No relatório avaliado, os itens são classificados e as ações são priorizadas de acordo com o maior grau de risco apresentado por cada desvio detectado. O plano de ação do fornecedor é gerenciado pelo mesmo e acompanhado em reuniões mensais com o cliente.

Em alguns casos onde houve um resultado muito crítico do fornecedor, ocorre a posterior auditoria de análise para garantir que o mesmo cumpriu as ações conforme detalhado no plano de ação. Na quarta etapa levantou-se a pontuação dos fornecedores em um momento posterior ao das auditorias realizadas, sendo este o primeiro semestre de 2016. No gráfico 3 pode-se identificar a evolução do fornecedor após a aplicação da auditoria.

Exceto em apenas 3 fornecedores, os demais 12 apresentaram uma evolução significativa após a aplicação da auditoria de processo. Houve uma média de avanço nas pontuações no ano de 2016 de 17,7\% comparado ao ano de 2015. Ao entrevistar as áreas de qualidade e compras da empresa considerada na pesquisa, os funcionários também associaram a melhoria dos fornecedores ao método de auditoria aplicada. A auditoria não foi responsável somente para detectar os riscos envolvidos no subfornecedor, mas também por gerenciar um plano de ação mitigando os possíveis efeitos destes riscos. 


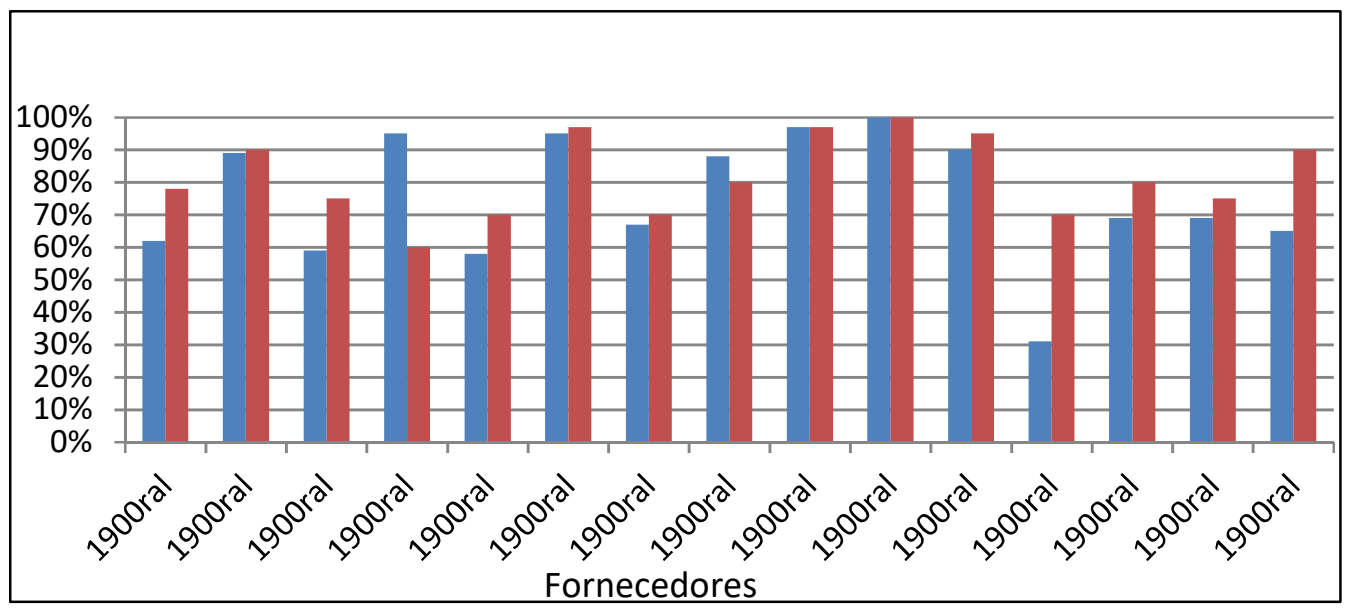

Gráfico 3: Comparativo de Pontuação 2015 vs 2016.

\section{CONCLUSÕES}

Após avaliar a sistemática de auditoria na empresa considerada na pesquisa, considerou-se uma similaridade com as etapas de gerenciamento de riscos descritas na norma ISO 31000: comunicação e consulta: ocorrem entre às partes interessadas internas da empresa avaliada por meio da comunicação do desempenho dos fornecedores para toda organização. Para as partes externas, são todas as tratativas feitas junto aos fornecedores para o planejamento, execução e acompanhamento da auditoria.

Consecutivamente, o estabelecimento do contexto: há o estabelecimento de contexto para garantir que a auditoria esteja alinhado com a cultura, processos, estrutura e estratégia da organização. São estabelecidos objetivos e critérios para a auditoria junto aos fornecedores; identificação dos riscos: esta etapa ocorre na detecção dos desvios durante a auditoria e relato dos mesmos no relatório. São apontados todos os riscos por meio do desvio de determinado requisito; análise de riscos: sobre os desvios detectados são analisados os potenciais efeitos que cada risco pode ter. São avaliados no relatório as causas e as fontes de risco, suas consequências positivas e negativas, e a probabilidade de que essas consequências possam ocorrer.

Após isso, tem-se a avaliação de riscos: a definição do plano de ação compreende na avaliação do risco, pois neste momento são definidos quais riscos precisam ser atuados, assim como o responsável e prazo; tratamento de riscos: a execução das ações estabelecidas na etapa anterior pretende mitigar e tratar os riscos identificados. São tratados os riscos de acordo com a prioridade estabelecida na avaliação de riscos; monitoramento e análise crítica: o gerenciamento do plano de ação, assim como as reuniões mensais de acompanhamento do plano com o cliente compreende justamente o monitoramento e análise crítica. É neste momento que deve-se garantir que as ações estejam sendo eficazes e eficientes, assim como detectar mudanças no contexto externo e interno, incluindo alterações nos critérios de risco.

Conclui-se portanto que a auditoria segue os passos de gerenciamento de risco da norma ISO 31000. Nos resultados apresentados, observa-se um aumento médio de $17,7 \%$ na pontuação dos fornecedores entre o ano de 2015 para 2016. Com isso prova-se por meio das evidencias na empresa avaliada que a auditoria colabora diretamente na evolução do desempenho dos fornecedores, podendo servir como um método eficaz de gerenciamento de risco de fornecedores. 


\section{REFERÊNCIAS}

ABNT. Associação Brasileira de Normas Técnicas. NBR ISO 9000:2005: Sistemas de gestão da qualidade: Fundamentos e vocabulário. Rio de Janeiro: ABNT, 2005.

ABNT. Associação Brasileira de Normas Técnicas. ISO 19011: Diretrizes para auditoria de sistemas de gestão. Rio de Janeiro: ABNT, 2012.

ABNT. Associação Brasileira de Normas Técnicas. NBR ISO 9001:2015: Sistemas de gestão da qualidade. Rio de Janeiro: ABNT, 2015.

AHMED, S. M.; AZHAR, S.; AHMAD, I.. Supply chain management in construction. Delhi Business Review, v.3, n.1, p.308-339, 2002.

ATTIE, W.. Auditoria Interna. São Paulo: Atlas, 1998.

BALLOU, R. H.. The evolution and future of logistics and supply chain management. Revista Produção, v.16, n.3, p.375-386, 2006.

BANDALY, D.; SHANKER, L.; KAHYAOGLU, Y.; SATIR, A.. Supply Chain Risk Management - II: A review of Operational, Financial and Integrated Approaches. Risk Management, v.15, n.1, p.1-31, 2013.

BLOS, M. F.; QUADDUS, M.; WEE, H. M.; WATANABE, K.. Supply chain risk management (SCRM): a case study on the automotive and electronic industries in Brazil. Supply Chain Management: An International Journal, v.14, n.4, p.247252, 2009.

CHRISTOPHER, M.; LEE, H.. Mitigating supply chain risk through improved confidence. International Journal of Physical Distribution \& Logistics Management, v.34, n.5, p.388-396, 2004.

CROXTON, K. L.; GARCÍA-DASTUGUE, S. J.; LAMBERT, D. M.. The Supply Chain Management Processes. The International Journal of Logistics Management, v.12, n.2, p.13-36, 2001.

FABIANI, S.; LAMO, A.; MESSINA, J.; RÕÕM, T.. European firm adjustment during times of economic crisis. IZA Journal of Labor Policy, v.4, n.1, p.24, 2015.

GIUNIPERO, L. C.; ELTANTAWY, R. A.. Securing the upstream supply chain: a risk management approach. International Journal of Physical Distribution \& Logistics Management, v.34, n.9, p.698-713, 2004

HOLLSTEIN, C.; HIMPEL, F.. Supply Chain Risk Management. Scientific Journal of Logistics, v.9, n.1, p.21-25, 2013.

KLEINDORFER, P. R.; SAAD, G. H.. Managing disruption risks in supply chain. Production and Operations Management Society, p.434-438, 2005.

LAMBERT, D. M.; POHLEN, T. L.. Supply Chain Metrics. The International Journal of Logistics Management, v.12, n.1, p.1-19, 2001.

MENTZER, J. J. T.. Defining supply chain management. Journal of Business Logistics, v.22, n.2, p.1-25, 2001.

NATOUR, A.; KIRIDENA, S.; GIBSON, P.. Supply chain integration and collaboration for performance improvement: an agency theory approach. Supply Chain and Services Management Symposium, p.503-519, 2011.

PLATTS, K. W.; GREGORY, M. J.. Manufacturing audit in the process of strategy formulation. International Journal of Operations \& Production Management, v.10, n.9, p.5-26, 1990.

PURDY, G.. ISO 31000:2009: Setting a new standard for risk management: perspective. Risk Analysis, v.30, n.6, p.881886, 2010.

ROBSON, K.; HUMPHREY, C.; KHALIFA, R.; JONES, J.. Transforming audit technologies: Business risk audit methodologies and the audit field. Accounting, Organizations and Society, v.32, n.5, p.409-438, 2007.

SINGHAL, P.; AGARWAL, G.; MITTAL, M. L.. Supply chain risk management: review, classification and future research directions. International Journal of Business Science and Applied Management, v.6, n.3, p.15-42, 2011.

TANG, C.. Robust strategies for mitigating supply chain disruptions. International Journal of Logistics, v.9, n.1, p.3345, 2006.

TANG, O.; MUSA, S.. Identifying risk issues and research advancements in supply chain risk management. International Journal of Production Economics, n.133, p.2534, 2011. 